\title{
PERNAMBUCO FALANDO PARA O MUNDO: A CULTURA PERNAMBUCANA E A FORMAÇÃO DE TERAPEUTAS COMUNITÁRIOS
}

\author{
THE CULTURE OF PERNAMBUCO AND THE FORMATION OF COMMUNITY \\ THERAPISTS
}

\author{
Marluce Tavares de OLIVEIRA ${ }^{1}$ \\ Verônica Chaves CARRAZZONE ${ }^{2}$ \\ Maria Aurea Bittencourt SILVA ${ }^{3}$ \\ Edna Maria MALHEIROS ${ }^{4}$ \\ Kátia SARAIVA ${ }^{5}$ \\ Cleide Ferreira NEVES ${ }^{6}$
}

RESUMO: O trabalho tem por objetivo explorar a história e utilização de elementos da cultura pernambucana na formação de terapeutas comunitários, conduzida pelo Polo Formador Espaço Família. A vertente utilizada, que parte da cultura como representação da relação das pessoas com sua história e tradições, tem se constituído como elemento de vinculação cultural, desde o uso peculiar da linguagem, cunhada Pernambuquês, à contribuição de músicas, danças e folguedos, com raízes pluriétnicas. Procede ainda ao relato histórico da implantação da TCI no Estado, passando pelo seu reconhecimento como prática integrativa complementar do SUS; há ênfase nas questões relacionadas com o uso do álcool e outras drogas, além dos diversos campos de utilização na assistência, no ensino e na pesquisa em saúde.

PALAVRAS CHAVE: Saúde pública. Terapias complementares. Antropologia cultural. Folclore. Autoestima.

ABSTRACT: The purpose of this study is to explore the history and use of elements of the Pernambuco culture in the formation of community therapists, conducted by the Polo Family Space. The part used as a representation of the relationship between people and their history and traditions, has been constituted as an element of cultural linkage, from the peculiar use of language, Pernambuquês, to the contribution of songs, dances with pluriethnical roots. It also records the history of the implantation of TCI in the State, passing through its recognition, as complementary integrative practice of

\footnotetext{
${ }^{1}$ Docente FCM/UPE, HC/UFPE, Doutora Saúde Materno-Infantil/IMIP, Terapeuta Familiar e Formadora em TCI/Espaço Família. Organização, redação, paródias, e revisão crítica final. marlucetavares.upe@gmail.com

${ }^{2}$ Docente, Psicóloga e Arte Educadora, Mestra em Sociologia e Formadora em TCI/Espaço Família. Redação e organização das referências bibliográficas. vecaz@bol.com.br

${ }^{3}$ Coordenadora e Formadora do Polo Formador em TCI/Espaço Família. Redação, ilustrações, formatação e revisão final.mabsilva@ hotlink.com.br

${ }^{4}$ Terapeuta Familiar e Formadora em TCI/Espaço Família. Redação. emalhei@ hotlink.com.br

${ }^{5}$ Socióloga, Especialista em Gerontologia, Formadora em TCI/Espaço Família. Pesquisa bibliográfica e revisão gramatical. Kmus13@homail.com

6 Docente aposentada SEd/PE. Formadora em TCI/Espaço Família. Pesquisa bibliográfica. cleideneves@hotmail.com
} 
SUS. The emphasis on issues related to the use of alcohol and other drugs, as well as the various fields of use in health care, teaching and research.

KEYWORDS: Public health. Complementary therapies. Cultural anthropology. Folklore. Self esteem.

A ABRATECOM deu a ideia

e Edna socializou.

O Espaço Família apoiando, com Marluce organizou.

Kátia fez pesquisa, que Cleide colaborou.

Herlinda e Verônica buscaram História e vivências, que Aurea embelezou.

Assim se deu esse relato que a tod@s profetizou: PERNAMBUCAN@S DA PESTE, VAMOS MOSTRARTEU VALOR! ${ }^{2}$

(AS AUTORAS)

\section{Pernambuco: és a fonte da vida e da história... ${ }^{3}$}

O processo de colonização de Pernambuco pelos portugueses teve início em 1501, formando assim uma das primeiras áreas brasileiras colonizadas, cujos ocupantes eram os índios Tabajaras. Com a instalação das Capitanias Hereditárias no Brasil (15341536), Pernambuco, onde foi iniciada a cultura da cana-de-açúcar, passou a ter importante papel na história econômica do país (PERNAMBUCO, 2015a), responsável por mais de metade das exportações brasileiras, sendo a mais promissora das capitanias da Colônia Portuguesa na América. Tal prosperidade chamou a atenção dos holandeses que aqui aportaram entre 1630 e 1654, quando o Conde Maurício de Nassau trouxe para Pernambuco uma forma de administrar inovadora. Data desta época a fundação, no Recife, da primeira sinagoga das Américas (PERNAMBUCO, 2015b).

O povo pernambucano aprendeu, desde cedo, a lutar por liberdade, gerando o espírito guerreiro e de amor à terra. Foi esta garra que fez com que os pernambucanos se unissem para derrubar o domínio holandês em 1645, quando teve início a Insurreição Pernambucana, o movimento de luta popular, com primeira vitória importante no Monte

${ }^{2}$ Paródia da música Paulo Afonso - Zé Dantas e Luiz Gonzaga

${ }^{3}$ Título alusivo ao Hino de Pernambuco (Brandão,1908) 
das Tabocas. Este movimento foi um marco importante para o Brasil, tanto militar, quanto sociopolítico, com o aumento da miscigenação (HOLANDA, 1971) entre as três raças (negro africano, branco europeu e índio nativo) e o começo de um sentimento de nacionalidade. As lutas em solo pernambucano, desde o Brasil Colônia até o questionamento do regime monárquico (Guerra dos Mascates, em 1710, e a Revolução Praieira, em 1848), instauram ares de mudança na perspectiva da res publica, onde pela primeira vez se falou em República no país. Os pernambucanos se orgulham de sua participação ativa na História do Brasil, sempre mantendo ideais libertários (HOLANDA, 1971).

Embora permanecesse marcado pela tradicional exploração do açúcar, a partir dos anos 60, ao sediar a Superintendência para o Desenvolvimento do Nordeste SUDENE, Pernambuco passou a reestruturar sua economia, ampliando as redes rodoviária e industrial, modernizando relações trabalhistas e liderando movimentos para o desenvolvimento do Nordeste, quando se consolidaram setores de ponta da economia, sobretudo o setor de serviços (turismo, medicina) e informática (Porto Digital) e, atualmente, encontra-se em fase de implantação de dois importantes polos industrialportuários (PERNAMBUCO, 2015c).

Localizado no centro leste da Região Nordeste do Brasil, com extensão territorial de 98.311 km²; Pernambuco conta com 8.796.032 habitantes (BRASIL, Censo do IBGE 2010), correspondendo a aproximadamente $4,6 \%$ da população brasileira. Cerca de $80 \%$ dos habitantes do estado moram em zonas urbanas.

Paralela a esses acervos históricos, existe uma versão não contada nos livros da história do Brasil (TRIBUNA DO NORTE, 2011), que dão aos pernambucanos o colorido mágico dessa tão falada expressão multicultural. A história "oficial" registrada nos nossos arquivos e até hoje ensinada nas nossas escolas desconhece o Brasil antes das invasões de 1500, negando assim a existência de um povo, de uma nação. Como se não bastasse a atrocidade do não reconhecimento dessa existência anterior a 1500, os registros mostram um índio que não é vítima de uma invasão, mas, ao contrário, um ingrato e indomável que não reconhece a honrosa missão civilizatória. Nega-lhes, a história, o direito de existir como verdadeiro povo bravo e guerreiro (PROGRAMA QUE HISTÓRIA É ESTA, 2012).

Nessa mesma direção, os povos capturados, trazidos ao Brasil para trabalho escravo, também têm sua existência negada. Os negros guerreiros, que bravamente 
lutaram para salvar seu povo e suas tradições, também não tiveram o direito de registrar suas histórias (FERREIRA NETO, 2017).

Unidos pelo mesmo ideal libertário e de preservação de seus valores, de suas crenças e de sua cultura, criaram grupos de resistência. Os quilombos são hoje sinônimo de agregação, resistência e resiliência. Homens e mulheres negros(as) que lutaram com dignidade em defesa do direito de ser também não estão nas páginas que arquivam os heróis da nossa história.

Essa consciência de uma memória histórica apagada carrega hoje um forte movimento de busca da própria origem, desse passado que precisa ser resgatado Nesse sentido, a TCI como ferramenta despertadora de memórias vem resgatando esses valores, provocando o empoderamento e conduzindo passo a passo para uma transformação social, que repensa políticas públicas que não se calam diante da vida. É na dança, na música, no movimento, nos sabores, nos fazeres e saberes que Pernambuco se ergue, com uma história que não precisa ser negada ou ofuscada, mas sim resgatada, pois empodera e revela esses bravos guerreiros.

O hino pernambucano é uma poesia em honra aos bravos guerreiros do estado e, em 2002, foi regravado nos ritmos de frevo, forró e manguebeat, com participação de artistas consagrados, como Alceu Valença, Dominguinhos e Cannibal. (Pernambuco, 2015)

Pernambuco é uma terra de muitos movimentos nativistas que tiveram impacto histórico determinante para o Brasil, com um povo festeiro, acolhedor e trabalhador, dedicado à arte de receber bem e cultivar as tradições e, ao mesmo tempo, é também o espaço da modernidade e das expressões contemporâneas no campo das artes, da tecnologia, da arquitetura, da música, da dança, do teatro, da culinária.

\section{CULTURA: Pernambuco Falando para o Mundo!}

Diz-se da cultura aquele conjunto complexo que traduz o conhecimento, a moral, leis, artes, crenças, costumes e outras aptidões e hábitos adquiridos por um povo vivendo em sociedade (MELLO, 2011), que nos remete aos processos de trabalho da Terapia Comunitária Integrativa - TCI e sua imbricação com a cultura, ao resgatar o jeito particular de ver e viver a vida. 
A cultura pernambucana é fortemente marcada pela diversidade cultural, constituindo um espaço pluriétnico, que encontra nas suas raízes os saberes e fazeres de índios, portugueses, holandeses, africanos, judeus e outros povos (PERNAMBUCO, 2015). Essa multiculturalidade pode ser identificada nas expressões literárias, musicais, teatrais, nas artes plásticas, arquitetura, danças, festas populares e religiosidade (BENJAMIN, 2011) do "Leão do Norte", representado no brasão do estado e bandeira do Recife, graças ao espírito combativo do seu povo e destacado na música homônima, dos compositores Lenine e Paulo César Pinheiro:

Sou o coração do folclore nordestino Eu sou Mateus e Bastião do Boi Bumbá Sou um boneco do Mestre Vitalino Dançando uma ciranda em Itamaracá Eu sou um verso de Carlos Pena Filho Num frevo de Capiba Ao som da orquestra armorial Sou Capibaribe Num livro de João Cabral

Sou mamulengo de São Bento do Una Vindo num baque solto de um Maracatu Eu sou um auto de Ariano Suassuna No meio da Feira de Caruaru Sou Frei Caneca do Pastoril do Faceta Levando a flor da lira Pra Nova Jerusalém Sou Luis Gonzaga Eu sou do mangue também

Eu sou mameluco, sou de Casa Forte Sou de Pernambuco, sou o Leão do Norte (bis)

Sou Macambira de Joaquim Cardoso

Banda de Pife no meio do Canavial Na noite dos tambores silenciosos Sou a calunga revelando o Carnaval Sou a folia que desce lá de Olinda O homem da meia-noite puxando esse cordão Sou jangadeiro na festa de Jaboatão

Eu sou mameluco, sou de Casa Forte Sou de Pernambuco, sou o Leão do Norte (bis)

Figuras 1 e 2: Maracatu e Caboclinhos Turma 2008-2009 

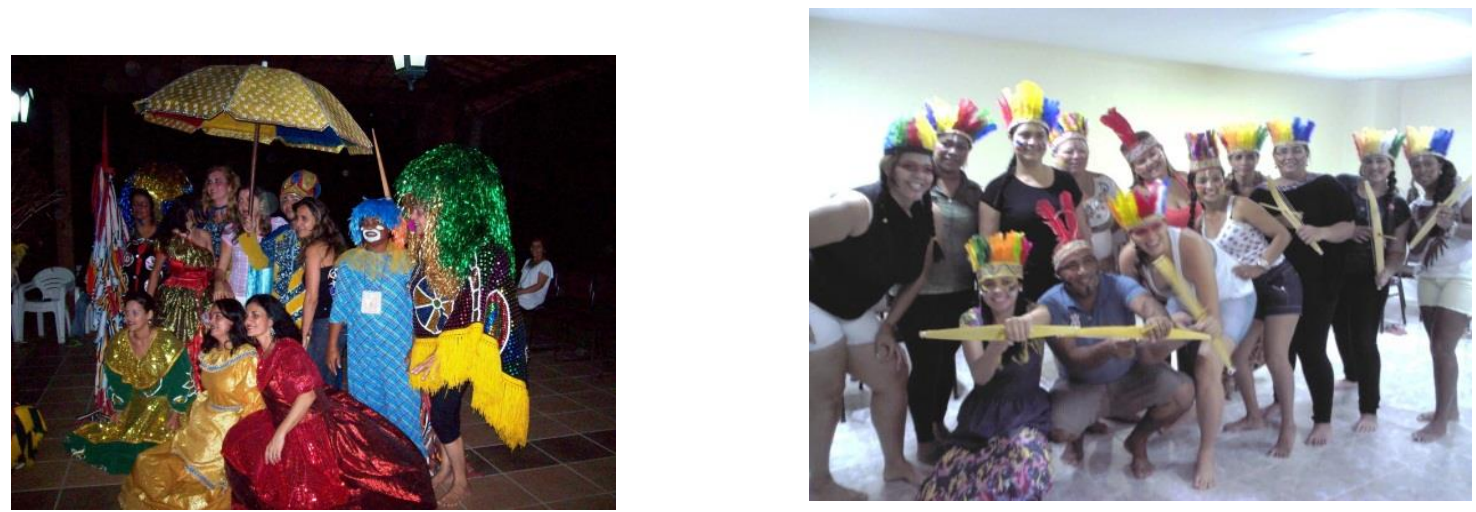

Fonte: Arquivo Pessoal.

Pela sua história, Pernambuco se destaca como um irradiador de cultura para a região Nordeste e o Brasil, e deles sofre influência, contribuindo para o amálgama de uma cultura genuinamente brasileira, contando com a contribuição de pernambucanos "da gema", aqui nascidos, ou que adotaram esta como a sua terra. As manifestações folclóricas consubstanciadas na poesia, canto, danças e folguedos populares (MELLO, 2011) encontram-se preservados no cotidiano do povo. Para além da efervescência cultural sintetizada na música Leão do Norte, temos todo um "caldeirão cultural" temperado com Coco de Roda, Bacamarteiros, Caboclinhos, Reisado, Quadrilha junina, Mamulengo, Cavalo-Marinho, Fandango e tantos outros folguedos (FILHO, 1999).

A religiosidade dos pernambucanos também se traduz no exercício de ritos de passagem (MELLO, 2011) e de graças alcançadas, como a festa de Jaboatão, consolidadas em vários ciclos: o Quaresmal (Noite dos tambores silenciosos no Carnaval, abrindo a quarta-feira de Cinzas; Via crucis, procissões, ladainhas), cujo maior expoente é a Paixão de Cristo de Nova Jerusalém, divulgado como o maior teatro ao ar livre do mundo; o Ciclo Junino que, na sua vertente profana (quadrilhas, Forró do Candeeiro e Pé de Serra, Xaxado, Baião) leva anualmente centenas de milhares de pessoas à cidade de Caruaru, no agreste do estado, onde se estabelece uma saudável rivalidade com a paraibana Campina Grande, pelo título de maior São João de Mundo; e o Ciclo Natalino (Autos, fandangos, Queima da lapinha), alguns desses, como o pastoril (VALENTE, 2015), embora em declínio na sua forma mais tradicional, tem estimulado a manutenção de uma geração de brincantes, resgatados na arte de Antônio da Nóbrega. 
As artes cênicas e o artesanato representam a relação das pessoas com sua história e tradições (MELLO, 2011).

O fazer artesanal pernambucano (PERNAMBUCO, 2015) se revela através das mais variadas expressões, seja, na arte de Lula Vassoureiro, que recebeu em 2014 o título de Patrimônio Vivo de PE e é a maior referência nacional e internacional (Europa, Ásia, Estados Unidos, México e Canadá), no que diz respeito à confecção de máscara dos "Papangus", seres imaginários ícones do carnaval da cidade de Bezerros; no couro e metais, base para a produção da vestimenta típica do vaqueiro, cuja tradição maior, a Missa do Vaqueiro (VICTOR, MELLO, FINIZOLA, 2012), é celebrada anualmente entre julho e agosto, na cidade de Serrita, no sertão; na madeira são talhados, de maneira rústica, os mundos mágico, romântico e trágico, que tem como expoentes J. Borges, conhecido dentro e fora do país como um dos melhores xilógrafos e poetas populares, retratando todo o universo cultural que descreve a vida do povo nordestino, do cangaço, dos folguedos populares, da religiosidade, dos milagres e mistérios; e Samico, que traz um universo imaginário, mágico, mitológico e fantástico como sua marca característica; e no barro, onde o grande Mestre Vitalino deixou um legado pulsante no Alto do Moura, em Caruaru, que se irradia "para o Brasil e o Mundo" a partir da Feira de Caruaru, imortalizada na canção de mesmo nome de Onildo Almeida e Luiz Gonzaga, o Rei do Baião:

\author{
A feira de Caruaru \\ Faz gosto da gente ver \\ De tudo que há no mundo \\ Nela tem pra vender \\ Na feira de Caruaru \\ Tem massa de mandioca (...) \\ Cenoura, jabuticaba, \\ Guiné, galinha, pato e peru \\ Tem bode, carneiro e porco \\ Se duvidar isso é cururu (...) \\ Tem cesto, balaio, corda \\ Tamanco, greia, tem boi tatu (...) \\ Tem rede, tem baleeira, \\ Mó de menino \\ Caçar nhandu (...) \\ Boneco de Vitalino \\ Que são conhecido inté no Sul \\ De tudo que há no mundo
}




\section{Tem na feira de Caruaru Na feira de Caruaru...}

$\mathrm{Na}$ busca de criar e difundir uma música erudita brasileira, de "raízes populares de nossa cultura", o Movimento Armorial, capitaneado pelo Mestre Ariano Suassuna, foi oficialmente lançado em outubro de 1970 (MAXWELL, s/d), inserindo-se na perspectiva do cultivo e valorização, respeito e preservação da cultura popular, como objeto de estudo, conhecimento e aprendizado. Esse movimento, por seu caráter cultural, social, literário, poético, político, educativo e artístico (LIMA, GUEDES, s/d) passou a agregar uma gama de manifestações artísticas que buscaram inspiração no romanceiro popular, que tem suas raízes no modelo ibérico-medieval que penetrou no Brasil, retratando cenas misteriosas como as narradas na literatura de cordel. Destacamse na rica produção artística desse paraibano de nascimento, que abraçou a cidade do Recife, na década de 40 (DIÁRIO DE PERNAMBUCO, 2015b), tornando-se cidadão pernambucano em 2005 (ALEPE, 2005): aulas-espetáculo; A pedra do Reino e O Auto da Compadecida, transformado em filme pelo cineasta pernambucano Guel Arraes que, junto com Cláudio Paiva e Newton Moreno dirigiu o seriado Amorteamo, da Rede Globo, baseado no livro Assombrações do Recife Velho, de Gilberto Freire.

Este rico ambiente criativo, onde confluem influências desde os tempos de Nassau (MORAIS, 2015), à Casa Grande \& Senzala de Gilberto Freire, à poesia de Ascenso Ferreira, Manuel Bandeira e João Cabral de Melo Neto e às movimentações tropicalistas no Nordeste, inspirou uma ampla gama de talentos locais, citando-se Luzilá Gonçalves, Jomard Muniz de Britto, Fátima Quintas, com produção literária em prosa e poesia; passando pelas oficinas literárias promovidas por Raimundo Carrero (2015); Ronaldo Correia de Brito, médico, escritor e dramaturgo, que concilia a tradição regionalista (Baile do Menino Deus, em parceria com Assis Brasil e Antônio Madureira) com processos de renovação cultural, sendo considerado um dos expoentes da contemporaneidade literária brasileira.

Na música, de ontem e de hoje, fervilham o Forró, Xaxado, Baião, embalados por cantadores, violeiros, repentistas e emboladores (FILHO, 1999); a Jazz Band Orquestra e o Frevo de Capiba; Nélson Ferreira, Luiz de França, Getúlio Cavalcanti e Levino; o Quinteto Violado, a Banda de Pau e Corda, Ave Sangria, Marco Polo, Babuska, Geraldo Azevedo, Alceu Valença e a Ciranda de Lia de Itamaracá (CAMPOS, 2010a). No Manguebeat, Chico Science e Nação Zumbi (DIÁRIO DE 
PERNAMBUCO, 2015), Mundo Livre S/A, Zé Brown e as Faces do Subúrbio, João do Morro, Otto, Karina Buhr e tantos outros pontilham a movimentada cena musical atual.

Nas artes plásticas, desponta o legado de artistas como Cícero Dias, Lula Cardoso Ayres, Murillo de La Greca, Romero Britto, Tereza Costa Rego, Francisco Brennand e Abelardo da Hora, cujas obras encontram-se espalhadas pelos quatro cantos do país, inclusive no exterior. O cinema, por sua vez, tem encontrado no CINE-PE Festival Audiovisual e na Janela Internacional de Cinema do Recife, respectivamente nas XVIII e VII edições em 2015, uma fecunda fonte de fomento, tanto para produções locais como para trabalhos de cineastas nacionais e internacionais.

Outro diferencial do ser pernambucano diz respeito ao uso peculiar da linguagem e comunicação (MAIOR, 1992), que, ao contrário de tempos passados em que era alvo de chacota fora do circuito nordestino, atualmente tem se constituído em elemento de resgate da autoestima e orgulho, a ponto de serem lançados em diversas mídias, Dicionários de Pernambuquês, como a compilação realizada por Fernando Tildes, João Bôsco Pinto e Paula Mendes (2015). Este linguajar, entretanto, vem a muito perpetuado na poesia de cordel, exemplificada no Cordel do Pernambuquês, de autoria de Daniel Bueno (s.n.t.):

Recife tem o glossário Do mais belo linguajar Do doutor, do operário...

Um vasto manancial

De termos peculiares

Recifense fala assim:

O liso tá sem dinheiro

Risada boa é gaitada

Mau pagador é xexeiro

Pé de cana é cachaceiro (...)

Por isso que tenho sorte

E me sinto envaidecido

De ter um dia nascido

Aqui no Leão do Norte

Pernambuco firme e forte

De um passado glorioso

Meu Recife prazeroso

De alvissareiro futuro:

Aqui me sinto seguro

Um cordelista orgulhoso...

A TCI entre Esses montes e vales e rios do Pernambuco 
Trazida para Pernambuco, no final da década de 90, pela Pastoral da Criança, a TCI ficou vinculada à Igreja Católica, tendo pequena divulgação no estado. Já em 2001, o Prof. Roberto Faustino, participante de curso de Terapia Comunitária (o Integrativa somente foi acrescentado cerca de 10 anos depois!) ministrado pelo Prof. Adalberto de Paula Barreto, no Ceará, promoveu oficina sobre a TCI, no curso Terapia Familiar Sistêmica da Universidade Federal de Pernambuco, UFPE, sob sua coordenação, despertando o interesse da então “TC”. Em 2003 realizou-se a primeira capacitação de terapeutas comunitários de Pernambuco, realizada em Olinda, pela Aquarius - Núcleo de Atividades Científicas (aquariusnac@gmail.com) e ministrada pelo Prof. Adalberto, com colaboração da Dra. Maria Henriqueta Camarotti, fundadora do MISMEC-DF. O impacto positivo do grande número de Rodas de TCI realizadas na Região Metropolitana do Recife, pelos participantes desta turma, tornou-a não apenas conhecida em PE, como também reconhecida como estratégia eficiente e eficaz, em vários contextos públicos e privados do Estado, motivando a capacitação de novas turmas.

O reconhecimento, em 2004, da TCI como política de prevenção e apoio nas questões relacionadas com o uso do álcool e outras drogas, pela SENAD, então Secretaria Nacional Antidrogas, originou o Convênio 16/2004, SENAD/UFC/MISMEC-CE, para realização do Curso de Formação em Terapia Comunitária, com Ênfase nas Questões Relativas ao Uso de Álcool e Outras Drogas, em 12 estados, incluindo Pernambuco, ministrado em 2006/2007 pelo recém-criado Polo Formador em “TC”, do Espaço Família Serviços Jurídicos e Terapêuticos.

A partir do reconhecimento pelo Ministério da Saúde da "TC" como prática integrativa complementar (2007), realizaram-se dois convênios federais para capacitação de trabalhadores de unidades de Saúde da Família de 15 estados, e um terceiro, para Capacitação em TCI com ênfase em situações de calamidades (20132015), também contemplando Pernambuco, ministrados pelo Espaço Família. Hoje, temos mais de 600 terapeutas comunitários, capacitados e em formação, nas 16 turmas promovidas em Pernambuco, oito por cada um dos dois Polos Formadores!

Eventos significativos direcionados aos terapeutas comunitários também foram realizados no estado: Encontro Norte Nordeste (2003), Mostra Pernambucana de 
Terapia Comunitária (2004), Encontro Pernambucano de Terapia Comunitária (2007) Encontro Nacional de Formadores em Terapia Comunitária (2008).

Figuras 3 e 4: Encontro Nacional de Formadores - Recife 2008
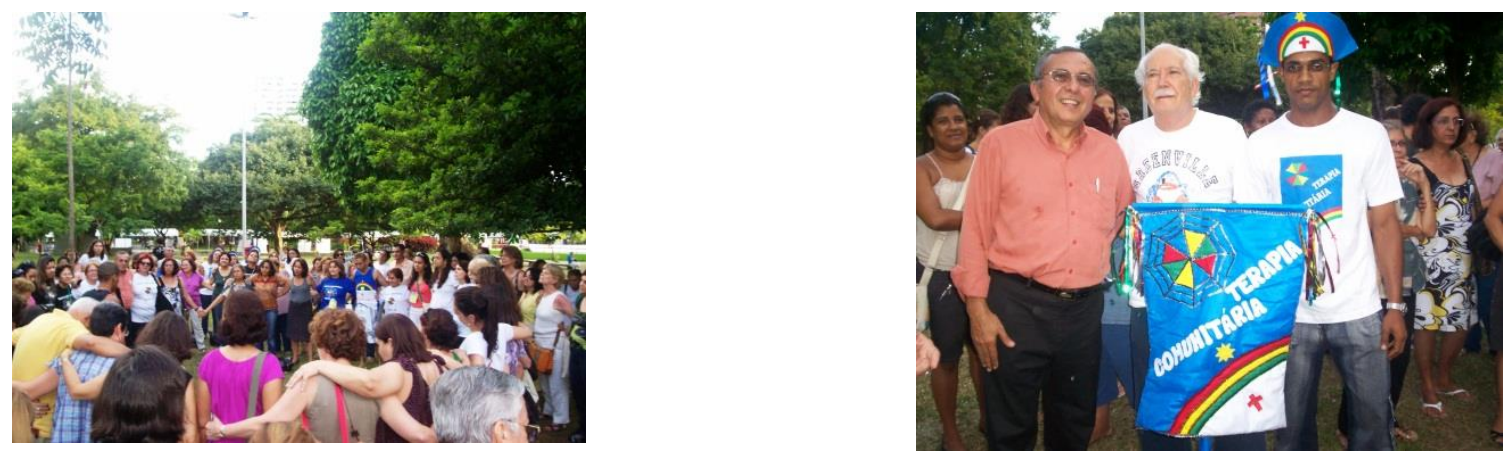

Fonte: Arquivo Pessoal.

A oferta de rodas de TCI no estado vem se ampliando no cotidiano de vários órgãos e instituições públicas (Hospital das Clínicas/UFPE; SIS/UFPE - Serviços Integrados de Saúde; diversas unidades municipais da Estratégia Saúde da Família, NASF e CAPS, em várias Regionais de Saúde do estado; FUNASE; SESI/Programa ViraVida), instituições religiosas Católicas, Evangélicas e Espíritas (em espaços paroquiais, creches e outros); empresas privadas (INTERNE, CECAF, ASSISTA, entre outras) e Organizações Não Governamentais - ONGs (Espaço Família, Amor Exigente, Pastoral da Mulher - Petrolina, Centro de Mulheres do Cabo, entre outras).

O ensino da graduação e pós-graduação latu sensu, a pesquisa e a extensão vêm se consolidando como importantes espaços de atuação da TCI em Pernambuco:

- incorporação como campo de práticas e oportunidades de reflexão educativa e autocuidado para alunos de graduação de Medicina/UFPE;

- cursos de atualização em Violência Intrafamiliar;

- residentes dos Programas Multiprofissional em Saúde Coletiva e de Medicina de Família e Comunidade;

- alunos bolsistas e voluntários de vários Projetos de Extensão e Pesquisa da Universidade de Pernambuco/UPE, em parceria com o ANINHAR: Grupo de Estudos e Intervenção em Saúde Comunitária e Família - CNPq/UPE . 
Muitos destes últimos, financiados pelo Conselho Nacional de Pesquisa/CNPq, Fundação de Amparo à Ciência e Tecnologia/FACEPE, Ministério da Saúde/ProPETSaúde/2012, além da própria UPE.

\title{
Elementos da cultura local usados nas Rodas de TCI e na Capacitação de Terapeutas Comunitários
}

\author{
E a TCI que é cearense, ui, ui, ui, ui \\ Brilhou ao chegar no Recife, ai, ai, ai, ai \\ Um toque, um sotaque pernambucano, ui, ui, ui, ui \\ Pintou uma nova energia, ai, ai, ai, ai
}

(Paródia da música Vassourinha Elétrica - Moraes Moreira)

A diversidade cultural de Pernambuco permite o uso significativo de diferentes expressões culturais, tanto na realização das rodas de TCI, quanto na formação dos terapeutas comunitários. No texto a seguir é possível experimentar um pouco do toque, da cor, do cheiro e do sabor dessa TCI, que ganha um "xodó" todo especial em terras pernambucanas.

\section{O Centramento Pernambucano}

Criado pelo Polo Formador Espaço Família, traz duas fortes referências; de um lado, o "Manual: Cuidando do Cuidador - resgate da autoestima na comunidade" e, de outro, o trabalho com terapia corporal da psicóloga Lucina Araújo, fundadora do Instituto LIBERTAS ( $w w w . l i b e r t a s . c o m . b r)$, utilizando os ritmos pernambucanos para liberar tensões dos sete segmentos corporais em que elas se concentram, segundo a teoria de Wilhelm Reich. Do manual, o Centramento do Corpo e da Mente, e da terapia corporal, o trabalho com o corpo a partir dos ritmos pernambucanos. Dessa junção, nasce um trabalho inusitado, alegre, com forte enraizamento cultural e grande poder de cuidado, ao qual nomeamos CENTRAMENTO PERNAMBUCANO. Originalmente adaptado para o encontro de formadores realizado em Pernambuco (ABRATECOM/ Aquarius/Espaço Família, 2008, Recife), passou a ser incorporado como técnica nas turmas de capacitação do Espaço Família, para liberar as tensões de forma animada e contextualizada. 
Começamos com o PASTORIL, fazendo o acolhimento, chamando e saudando para iniciar o trabalho; depois vem o XAXADO que trabalha com os pés, e assim o nosso enraizamento, a fundação do corpo; seguido do COCO e do CABOCLINHO que mexem com as pernas, apêndice da pélvis, ou seja, a nossa energia vital, nossa luta pela sobrevivência, impulsionando nosso desejo de mudança; seguido do FORRÓ, que movimenta a região da cintura, estimulando a criatividade, e movimentando também o estômago, possibilitando a digestão das mágoas e o perdão; em seguida o MARACATU que, no abrir e fechar os braços, movimenta o tórax, o diafragma, trabalhando a reciprocidade, o dar e o receber; finalmente chegamos ao FREVO, e nesse momento, a energia que ainda não foi desbloqueada, será aqui trabalhada, no frevo tudo se mexe, a timidez a insegurança, preconceitos e nossa capacidade de compreensão; fecha-se o trabalho com uma CIRANDA, dança democrática, de aceitação, em que todos dançam de mãos dadas num círculo, representação da nossa espiritualidade, elevação e conexão com o divino, em que todas as diferenças são dançadas harmonicamente, numa reunião fraternal.

\section{As danças circulares}

A dança como união do corpo e do som, no seu movimento faz com que a energia circule, promovendo saúde, pois não permite a estagnação da energia no corpo. $\mathrm{Na}$ vida cultural brasileira e pernambucana, em particular, as danças de roda possuem presença marcante, com tradições ancestrais marcadas pela mistura e influências indígenas, afro-brasileiras e europeias. Assim, as Danças Circulares (também conhecidas como Danças Circulares Sagradas ou ainda Danças dos Povos) têm reunido pessoas para vivenciar em conjunto experiências afetivas, subjetivas e educativas de construção de uma cultura da paz, na qual os corpos em movimento se tocam e se confraternizam, repensando e reposicionando formas de sociabilidades e de práticas culturais na contemporaneidade (SANTOS, 2015).

Usada na abertura e no encerramento de rodas de TCI e módulos de formação, possibilita reflexão sobre ação e a tomada de consciência desse cuidado. Muitas são as danças circulares usadas na TCI: Ciranda, Desanda roda, A Linda Rosa Juvenil, entre outras. 
A ciranda é uma dança circular originária do litoral norte de Pernambuco, caracterizada pela formação de uma grande roda, geralmente nas praias ou praças, onde os integrantes dançam ao som de música de ritmo lento e repetido, acompanhada por tocadores e dançarinos e entoada por mestre cirandeiro, cuja expressão maior, Lia de Itamaracá, é considerada Patrimônio Vivo de Pernambuco. Na marcação do bombo, os cirandeiros pisam forte com o pé esquerdo à frente. Num andamento para a direita na roda de ciranda, os dançarinos dão dois passos para trás e dois passos para frente, sempre marcando o compasso com o pé esquerdo à frente. É uma dança comunitária amplamente inclusiva, sem restrições de idade, cor, classe social ou raça, sem limite de participantes, podendo, como as rodas de TCI, se iniciar com um pequeno número de pessoas e ir aumentando, à medida que se desenvolve (GASPAR, 2015a). A permissão de improvisar versos de acordo com o contexto, uma das suas características marcantes, oportuniza ampla expressão das emoções pelos participantes, tão bem-vinda nas Rodas e capacitações em TCI.

\author{
Vamos fazer a roda \\ Juntando mão com mão \\ Vamos prá terapia \\ Aliviar a tensão \\ A terapia não é minha só. \\ Ela é de todos nós! (Bis
}

A Desanda Roda pode ser usada em diferentes momentos, mas tem sido bastante utilizada para encerramento de módulos nas capacitações. Todos em círculo fazem duplas, cumprimentam o seu par e seguem seu caminho como no passo do "granchê" da quadrilha; ao final da música, abraça-se a pessoa que estiver de mãos dadas com você. Todos cantam a seguinte música: "Anda roda, desanda roda, que eu quero encontrar a flor, aquela que for mais bela, com ela me abraçarei”. Deve ser repetida por 3 ou 4 vezes, buscando cada vez mais ajustar o ritmo e a sintonia do grupo. Cantada e dançada conjuntamente, possibilita refletir sobre as pessoas significativas da nossa vida, que cortejamos e seguimos nosso caminho, possibilitando que outros encontros significativos aconteçam; o medo de ficar só ou de ser abandonado; a tranquilidade para aguardar o momento certo para abraçar, além da flexibilidade para compreender os diferentes ritmos de cada pessoa; valorizando o que cada encontro oferece de especial, 
são possibilidades vivenciadas nessa dança. Sua utilização no acolhimento de rodas de TCI, habitualmente, traz muita alegria e sintonia com os desencontros frequentes na quadrilha junina e pode servir como elemento importante para a emergência de temas ao facilitar o link com as dificuldades do cotidiano.

A linda Rosa Juvenil é uma dança circular muito conhecida entre as crianças; é usada tanto nas rodas como nos módulos e intervisões da formação em TCI, pois traz excelente reflexão sobre os diferentes papéis que assumimos na vida. Todos em círculo seguem em movimento, com as mãos soltas, vão cantando e encenando cada trecho da música: "a linda rosa juvenil, juvenil, juvenil, vivia alegre no solar (ou seu lar), no solar, no solar; um dia veio uma bruxa má, muito má, muito má; e adormeceu a rosa assim, bem assim, bem assim; o tempo passou a correr, a correr, a correr; o mato cresceu ao redor, ao redor, ao redor; um dia veio um lindo rei, lindo rei, lindo rei; que despertou a rosa assim, bem assim, bem assim".

Permite que os sujeitos reconheçam seus diferentes fazeres diante da vida, em que protagonizamos a linda rosa desabrochando e plena de vitalidade; a bruxa má que adormece e anula a expressão do outro; somos também esse tempo implacável, que escraviza e alerta; o mato que ofusca e impede a expressão das pessoas; mas também somos esse rei maravilhoso, que promove saúde, esse Terapeuta despertador de lembranças, que possibilita esse ressignificar da vida e facilita o processo de resiliência. Igualmente, seu uso no acolhimento de rodas de TCI pode facilitar a emergência de temas relativos ao autoboicote e descrença na capacidade pessoal, como na construção do mote e durante a problematização, pode ajudar a fazer a síntese e o resgate da autoestima e crença em si mesmo, que iluminam as possibilidades de superação partilhadas no grupo.

O toré é uma dança indígena também considerada uma dança circular sagrada, possui diferentes modalidades, desde o agradecimento aos deuses e preparação, até o pedido de proteção para a caça e para as batalhas. Faz parte da cultura autóctone dos povos índios de Pernambuco: Kariri-xocó, Xucuru-kariri, Pankararú e Tuxá (GASPAR, 2015b). A que usamos na TCI é "Juruguruná": todos virados para o centro do círculo cantam e acompanham o ritmo da música, cuja variação da coreografia é dividida em 5 momentos: 1 - braços entrelaçados, com os joelhos flexionados, dando passos bem marcados para a direita "Jurugunurá, tatá, de goiazes, ê (repete); 2 - joelhos flexionados, braços soltos, vai batendo o pé direito, caminhando para o centro do círculo, ficando bem amontoados, e na repetição vão caminhando para trás, abrindo o 
círculo novamente "Aê, aê, ê, eu quero ver Juruguruna trabaià (repete)"; 3 - 3 passos para frente, em direção ao centro do círculo e bate uma palma, virando de costas e retornando para fora com 3 passos também, e bate uma palma ao final "Itacolomi deu estrondo, pedra grande gemeu (repete); 4 - Joelhos flexionados vai em direção ao centro, batendo forte o pé direito "e quem estava em cima da pedra"; 5 - continua virado para o centro do círculo e volta de costas, levantando os braços 3 vezes e gritando bem alto "era eu, era eu, era eu"

Essa dança expressa exatamente o movimento sagrado da preparação para a ação, todos se sentem fortalecidos e emocionados, confiantes de que se prepararam e que agora é a hora do fazer, com garra, contando com o apoio dos demais terapeutas e formadores.

\section{Dinâmica choque cultural}

Dinâmica que propõe uma encenação sobre o modo de vida de pessoas com culturas diferentes (PORTAL DA FAMÍLIA, 2015). É usada na formação, especificamente no módulo de Antropologia Cultural; juntamente com a teoria, possibilita reconhecer, valorizar e respeitar as diferenças e riquezas culturais, percebendo a cultura como dimensão de tudo o que se faz em cada grupo humano e como a identidade de um povo. Amplia o olhar do Terapeuta comunitário para as possibilidades culturais de cada grupo e para os valores e crenças como estruturadores de contextos e modos de vida.

Os passos são: dividir a turma em três equipes; uma equipe vai encenar a tribo indígena chegando à cidade; outra equipe encena um grupo de operários encontrando um grupo indígena; a terceira equipe será observadora e avaliadora das encenações. Vivenciar esse choque das dimensões culturais reativa lembranças de nossas raízes, possibilitando uma imersão na legitimidade da estruturação do saber-fazer-ser do outro.

Figura 6: Dinâmica Choque Cultural - Turma 2012/2013 


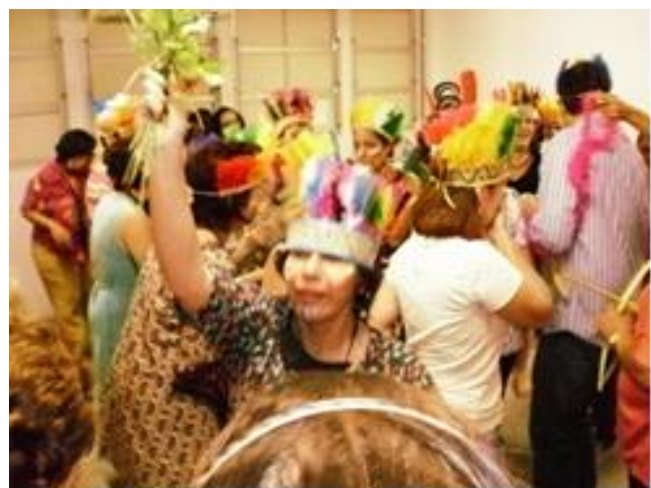

Fonte: Arquivo Pessoal.

\section{Cordel, ditados, músicas, jogos, paródias e expressões populares}

No acolhimento de rodas de TCI, a confluência da literatura de cordel com ditados populares (CAMPOS, s/d) tem sido explorada de diversas maneiras: exemplificando situações partilhadas na contextualização e problematização, ou na forma de jogral, no acolhimento. Durante o módulo de Paulo Freire, um cordel que permite trazer Paulo Freire, na essência do seu método, ou seja, através da realidade cultural pernambucana, é entregue a cada aluno (CAMPOS, 2010b). O mesmo se aplica aos ditados, paródias, músicas e danças populares, em que os saberes prévios são ressaltados, possibilitando a construção de novos saberes a serviço da transformação social. Durante toda a formação ou nas rodas de TCI vão sendo vivenciados e evidenciados os ciclos carnavalesco, junino, natalino, através das quadrilhas, pastoril, cirandas, frevos, maracatus, etc.

Os mimos e lanches (ABRIL Coleções, 2009) também acompanham a cultura, assim, o bolo de rolo, bolo de goma, a paçoca, o nego-bom, os chocalhos, a bonequinha da sorte, as mensagens e as decorações, entre tantas outras expressões, são cardápio fértil para formação de sujeitos com conhecimento e consciência cidadã, atentos ao seu papel político no mundo.

\section{REFERÊNCIAS}

ABRIL Coleções. Receitas das festas populares. São Paulo: Ed. Abril, 2009.

ALEPE - Assembleia Legislativa do Estado de Pernambuco. Todos os ritmos do toadas de Pernambuco. Disponível em: 
<www.alepe.pe.gov.br/downloads/Tribuna/200506.pdf>. Acesso em: 25 mai. 2015.

BENJAMIM, R. Cultura pernambucana. João Pessoa: Editora Grafset, 2011.

BUENO, D. Cordel do pernambuquês, (s.n.t.).

BRASIL. Instituto Brasileiro de Geografia e Estatística. CENSO 2010. Disponível em: <http://www.censo2010.ibge.gov.br> Acesso em: 18 mai. 2015.

CARRERO, R. Oficina de criação literária. Disponível em:

<www.raimundocarrero.com.br/oficina_pt.php>. Acesso em: 28 abri. 2015.

CIS - Centro Integrado de Saúde. Saúde holística e alternativa. Disponível em:

$<$ https://www.facebook.com/pages/CIS-Centro-Integrado-de-

Sa\%C3\%BAde/473420549360187?fref=ts>. Acesso em: 24 maio 2015.

DIÁRIO DE PERNAMBUCO. O que foi o Movimento Manguebeat? Disponível em: <http://www.diariodepernambuco.com.br/app/noticia/diarinho/2014/02/21/interna_diari nho,490736/o-que-foi-o-movimento-manguebeat.shtml>. Acesso em: 26 mai. 2015.

DIÁRIO DE PERNAMBUCO. Ariano Suassuna. Disponível em:

$<$ http://www.diariodepernambuco.com.br/especiais/viver/ariano-

suassuna/\#sthash.HW1yv3nu.dpuf>. Acesso em: 20 mai. $2015 b$.

FERREIRA NETO, C. Indígenas e negros no Vale do Jaguaribe: entre o cativeiro e a liberdade. Disponível em:

<http://www.apeoc.org.br/extra/artigos_cientificos/Indigenas_e_Negros_no_Vale_Jagu aribe.pdf>. Acesso em: 30 jan. 2017

FILHO, C. F (Org.). Espetáculos populares de Pernambuco. Recife: Bargaço, 1999.

GASPAR, L. Ciranda e Danças indígenas do Brasil. Pesquisa Escolar Online, Fundação Joaquim Nabuco, Recife. Disponível em:

<http://basilio.fundaj.gov.br/pesquisaescolar/>. Acesso em: 21 mai. 2015.

GONZAGA, L. A feira de Caruaru. Disponível em: <http://letras.mus.br/luizgonzaga/204732>. Acesso em: 20 mai. 2015.

HOLANDA, S. B. Raízes do Brasil- Coleção Documentos Brasileiros n. 1. 6 ${ }^{\mathrm{a}}$. ed. Rio de Janeiro: Ed. José Olympio; 1971.

LENINE. Leão do Norte. Disponível em: <http://letras.mus.br/lenine/88967/>. Acesso em: 20 mai. 2015.

LIMA, C.; GUEDES, S. O reino mágico da xilo (gravura). Disponível em: <http://www.unicap.br/armorial/35anos/trabalhos/o-reino_xilogravura.pdf>. Acesso em: 20 mai. 2015.

MAIOR, M.S. A língua na boca do povo. Recife: FUNDAJ, Ed. Massangana, 1992. 
MAXWELL, V. R. A. C. Introdução: Ariano Suassuna e o movimento armorial. Disponível em <http://www.maxwell.vrac.puc-rio.br/9879/9879_2.PDF>. Acesso em: 20 abr. 2015.

MELLO, L. G. Antropologia cultural: iniciação, teoria e temas. 18ª ed. Petrópolis, Ed. Vozes, 2011.

PERNAMBUCO, Governo do Estado de. História de Pernambuco. Disponível em: <http://www.pe.gov.br>. Acesso em: 18 maio 2015a.

PERNAMBUCO. Portal da Cultura de Pernambuco. Disponível em: $<$ https://www.cultura.pe.gov.br/pagina/patrimonio-cultural/>. Acesso em: 05 abri. $2015 b$.

PERNAMBUCO. SECTEC - Secretaria de Ciência, Tecnologia e Inovação. Disponível em: 〈http://www.lai.pe.gov.br/web/sectec>. Acesso em: 05 abr. 2015c.

PORTAL DA FAMÍLIA. Dinâmicas de grupo - 2. Disponível em:

<http://www.portaldafamilia.org/sclazer/jogos/dinamicas-em-grupo-2.shtml>. Acesso em: 28 abr. 2015.

PROGRAMA QUE HISTÓRIA É ESSA. Maluguinho. Negro/Índio Guerreiro de Pernambuco. Postada em 26 de fevereiro de 2012. Disponível em: <http://programaquehistoriaeessa.com.br/?p=163>. Acesso em 30 jan. 2017.

SANTOS, A. P. Dança circular. Disponível em:

$<$ https://dancacircularufabc.wordpress.com/o-que-sao-dancas-circulares/>. Acesso em 09 mai. 2015.

TILDES, F.; PINTO, J. B. A.; MENDES P. Dicionário pernambuquês. Disponível em:

<http://www.aisa.com.br/diciope.html>. Acesso em: 18 maio 2015.

TRIBUNA DO NORTE. A história não contada dos índios e negros da terra. Postado em 25 de julho de 2011 - 10h11. Disponível em: <http://www.vermelho.org.br/noticia/1595651>. Acesso em: 30 jan. 2017.

RECIFE. Porto das letras. Disponível em:

<http://www.recife.pe.gov.br/portodasletras/paginas/php/linhadotempo_poesia.php>. Acesso em: 20 maio 2015.

VALENTE, V. Pastoril. Disponível em:

$<$ http://basilio.fundaj.gov.br/pesquisaescolar/index.php?option=com_content\&view=arti cle\&id=608: pastoril\&catid=50:letra-p\&Itemid=1>. Acesso em: 20 maio 2015

VICTOR, A.; MELlO, F. P.; FINIZOLA, J. Missa do vaqueiro: 40 anos. Recife, Publikimagem, 2012. 


\section{Como referenciar este artigo}

OLIVEIRA, Marluce Tavares et al. Pernambuco falando para o mundo: a cultura pernambucana e a formação de terapeutas comunitários. Revista Temas em Educação e Saúde, Araraquara, v.12, n.2, p. 246-265, jul-dez/2016. ISSN: 1517-7947.

Submetido em: 10/11/2016

Aprovado em: 30/11/2016 